\title{
O sound design de Alan Splet para David Lynch sob a perspectiva do horror fílmico
}

\author{
Laura Loguercio Cánepa Correio' \\ https://orcid.org/0000-0003-3248-599X \\ Rogério Ferraraz' \\ https://orcid.org/0000-0002-7625-0554 \\ Fabiano Pereira de Souza' \\ https://orcid.org/0000-0001-7576-6631 \\ I - Universidade Anhembi Morumbi \\ São Paulo (SP). Brasil
}

Resumo: O sound designer americano Alan Splet (1939-1994) participou da produção de 25 filmes. Com o diretor David Lynch, criou efeitos sonoros e ambiências mais livres de vínculos com a verossimilhança. Eles trabalharam juntos no curta-metragem The grandmother (1970) e nos longas-metragens Eraserhead (1977), O homem elefante (The elephant man, 1980), Duna (Dune, 1984) e Veludo azul (Blue velvet, 1986). A forte influência surrealista na filmografia de Lynch estimulou soluções de Splet que se assemelham ao trabalho de som do gênero cinematográfico do horror, o que se reconhece até na recente temporada de 2017 da série de TV Twin Peaks, com direção e sound design do próprio cineasta. Este artigo aborda os procedimentos de edição de som mais usuais na filmografia desse gênero, comparados à edição de efeitos sonoros desse sound designer.

Palavras-chave: cinema; TV; sound design; horror fílmico; Alan Splet; David Lynch.

Abstract: Alan Splet's sound design for David Lynch from the perspective of film horror The American sound designer Alan Splet (1939-1994) participated in the production of 25 films. With director David Lynch he created sound effects and ambiences that were freer of links to verisimilitude. They worked together on the short film The Grandmother (1970) and the feature films Eraserhead (1977), The Elephant Man (1980), Dune (1984) and Blue Velvet (1986). The strong surrealist influence in Lynch's filmography stimulated Splet's solutions that resemble the sound work of the horror film genre, which is even recognized in the recent 2017 season of the TV series Twin Peaks, directed and with sound design by the filmmaker himself. This article deals with sound editing procedures that are more common in the filmography of this genre, compared to the editing of sound effects of that sound designer.

Keywords: cinema; TV; sound design; film horror; Alan Splet; David Lynch. 


\section{Introdução}

Ainda que tenha trabalhado com importantes cineastas da indústria cinematográfica americana entre os anos 1970 e 1990, o sound designer Alan Splet (1939-1994) é frequentemente lembrado pela peculiaridade de seu trabalho com o cineasta David Lynch (1946-). Ao valorizar efeitos e ambientes sonoros, Lynch abriu para ele um campo fértil para que explorasse, entre outros elementos, a assincronia entre sons e imagens e distorções de sons, como a voz, com efeitos e resultados em diferentes níveis. Sob a direção de Lynch, Splet participou, já em sua estreia no cinema, do quarto curta-metragem do diretor, The grandmother (1970), e dos longas-metragens Eraserhead (1977), O homem elefante (The elephant man, 1980), Duna (Dune, 1984) e Veludo azul (Blue velvet, 1986), filme que delimitou mais claramente temas e recursos de estilo que Lynch usaria em filmes seguintes, até mesmo nas temporadas - de 1990-1991, e ainda mais na de 2017 - da série de TV Twin Peaks.

Na série, destacam-se, em termos de experimentação sonora, as cenas oníricas, em que o agente Dale Cooper (Kyle MacLachlan) está num quarto vermelho, muitas vezes em companhia da falecida Laura Palmer (Sheryl Lee) ou de um anão (Michael J. Anderson), que Ihe falam de maneira estranha. Os atores diziam suas falas de trás para frente, e a cena era editada para exibição no sentido inverso, tornando as palavras quase incompreensíveis (RODLEY, 1997, p. 165-167). Embora Splet nunca tenha estado na equipe de produção de Twin Peaks, a ideia para esse efeito havia sido pedida a ele por Lynch na produção de Eraserhead, em 1971, para ser usada na cena da fábrica de lápis (ibidem).

Buscar reconhecer quais seriam as características singulares do design de som em Twin Peaks, e como a obra de Splet contribuiu para a criação da identidade artística autoral de Lynch, pede que se caracterize o tipo de trabalho que Splet realizou. Porém, para reconhecer nele semelhanças ou influências do som no cinema de horror - gênero em que, segundo o portal IMDb, Splet só atuou no curta-metragem Young Goodman Brown (EUA, 1972), de Donald Brown, vale caracterizar esse gênero em seus procedimentos mais recorrentes. Também é importante entender o que caracteriza a atividade do sound design para mensurar com mais precisão a contribuição de Splet.

Sound designer é uma função criada na década de 1970 para estabelecer uma identidade sonora para o filme inteiro, desde a concepção do projeto, aplicando - por meio da edição, de efeitos e de mixagem - efeitos correspondentes à estética visual prevista pelo diretor. Dessa forma, a função proporciona, durante toda a produção, a comunicação clara entre a equipe e os chefes de som direto, edição e mixagem, o que antes não era regra (MANZANO, 2013, p. 16). Depois de editar som com George Lucas em THX 1138 (EUA, 1971) e em Loucuras de verão (American graffiti, EUA, 1973), e de trabalhar para Francis Ford Coppola em O poderoso chefão (The godfather, EUA, 1972), A conversação (The conversation, EUA, 1974) e O poderoso chefão /I (The godfather: Part II, EUA, 1974), valorizando efeitos sonoros de forma inovadora, foi Walter Murch que 
cunhou o termo sound designer, quando trabalhava em Apocalipse now (EUA, 1979), pelo qual foi premiado com o Oscar de melhor som.

Para abordar o cinema de horror propriamente dito, é primordial resgatar suas origens na literatura. O fantástico, mais especificamente o sobrenatural, é um dos elementos-chave do gênero horror. Ele implica uma série de condições que levem o leitor a obter uma percepção ambígua dos acontecimentos narrados. Não se trata de um leitor em particular, real, mas sim de uma "função de leitor" implícita no texto. A hesitação do leitor é, pois, a primeira condição do fantástico (TODOROV, 2007, p. 37).

A noção de perigo à integridade física e o medo dele decorrente é um dos alicerces desse tipo de construção ficcional, seja ela literária ou cinematográfica. Seu recorrente organicismo é uma das fontes vitais do gênero. Pessoas em sã consciência nunca se sentem atraídas por podridão e decomposição física, mas, pela mediação simbólica da arte, podemos averiguar nossas aversões, medos, repulsas e suas implicações (MORGAN, 2002, p. 17).

Mutilações e deformidades físicas são tema recorrente nos filmes de Lynch. Só para se ater à parte da sua obra em que Splet atuou, Eraserhead apresenta um bebê deformado que acaba destroçado. O personagem-título de $O$ homem elefante tem uma deformação em sua cabeça e seu corpo, o que Ihe dá um aspecto abjeto. Em Veludo azul, a orelha decepada de um personagem é o estopim de uma investigação que leva o protagonista a um mergulho no lado sombrio e assustador de sua cidade.

O que desde cedo caracterizou o trabalho de som nos filmes de horror fora, especialmente, os tão característicos sons extracampo. São marcos iniciais do gênero em Hollywood: Drácula (Dracula,1931), dirigido por Tod Bowning, e Frankenstein (1931), de James Whale. A transição do cinema para o período sonoro funcionou como uma espécie de filtro que levou ao limite todos os outros materiais e forças que confluíram para os primeiros filmes sonoros de horror produzidos por Hollywood (SPADONI, 2007, p. 4).

Eis aí a primordial base de comparação entre os efeitos sonoros mais tradicionais do cinema de horror e o trabalho de Splet: os sons, frequentemente os não orais nem musicais, ouvidos de alguma origem fora do campo, e o fator de apreensão que eles causam por deixarem a plateia em busca de respostas para o que não se pode confirmar com os olhos, assim como costuma acontecer com personagens em cena. Sons que podem não vir de uma ação humana, daquela esfera de existência, daquele tempo e espaço. Existem impressões que podem servir de gatilho para sensações de mistério, entre as quais perceber momentaneamente um objeto inanimado como vivo ou algo vivo como inanimado (ibidem, p. 6).

\section{Sons horrorizantes}

O grito é um padrão sonoro do horror, sua representação mais concreta, por provocar na plateia o afeto deste sentimento. Isso explica a importância das "scream queens" 
(rainhas do grito), atrizes lembradas por papéis em que gritam muito (CARREIRO, 2011, p. 45). Essa qualidade, também válida para monstros e seus timbres graves e guturais, é uma das mais notórias a extrapolar a tradicional função semântica da voz no cinema. Assim como a trilha musical, os efeitos sonoros são bons recursos de "manipulação emocional dos espectadores" (ibidem, p. 47), amiúde vindos de fora de quadro. Entre as técnicas mais recorrentes estão a do som inesperado que gera susto, o deslocamento no espaço de sons de origem potencialmente ameaçadora, a identificação lenta dessa origem. "Portas rangendo, janelas batendo, grunhidos de animais e gritos de pavor estão entre os sons fora de quadro mais comumente utilizados em filmes de horror" (ibidem).

Não saber onde o monstro ou personagem que representa perigo está implica na percepção de que ele pode estar em qualquer lugar para um ataque a qualquer momento (ibidem, p. 48). A aparição repentina da personagem que representa o perigo, causa um efeito surpresa, um susto muitas vezes compartilhado entre a personagem em risco e a plateia. O som fora de quadro realça e potencializa a reação emocional do espectador. A aparição repentina é editada "em sincronia com um efeito sonoro, uma nota musical ou um grito, quase sempre em volume bem mais alto do que os sons que se pode ouvir imediatamente antes ou depois" (ibidem).

A reprodução sonora deu um salto qualitativo quando o sistema multicanal tornou-se regra nos anos 1970, dividindo a trilha sonora em quatro, cinco ou mais canais na própria cópia de 35mm (MANZANO, 2013, p. 16). Para o sound design, a melhor qualidade técnica na reprodução sonora da época propiciou mais sofisticação no emprego de efeitos, ambientes e mesmo do foley (sons adicionados na pós-produção para aprimorar a verossimilhança).

Surgiu também em Hollywood a primeira geração de cineastas vinda de faculdades de cinema nos Estados Unidos. A cultura fílmica desses novatos fazia com que acreditassem em novas formas de se trabalhar o som em cinema. Baseados em São Francisco, Califórnia, Coppola e Lucas se associam a dois dos primeiros e mais renomados sound designers, Murch e Ben Burtt, respectivamente. Diferentemente destes, Splet não teve formação acadêmica. Antes do cinema, era contador. Porém, por conta de uma deficiência visual, ele desenvolveu uma escuta apurada para sons e preferia gravar seus próprios efeitos, em vez de recorrer aos catálogos sonoros usuais.

A distorção ou substituição da voz, na pós-produção, por outros tipos de sons é usual no cinema de horror e ficção científica. Monstros que passam por deformação física, como vampiros e lobisomens, não raro, trazem vozes distorcidas. Em O exorcista (The exorcist, 1973), por exemplo, a menina possuída e fisicamente deformada fala com uma voz rouca bestial, características transferidas para o religioso que, para tentar salvá-la, pede ao demônio que o leve em seu lugar. Ciborgues, como Darth Vader (Guerra nas estrelas, 1977) ou Robocop (1986), apresentam vozes metalizadas, a exemplo de seus corpos humanos transformados em máquinas. 
O exorcista representa um marco da dissociação entre o corpo e a voz no cinema. Vencedor do Oscar de melhor mixagem sonora, o filme tem particularidades musicais, de voz e também de efeitos sonoros. A exemplo do que Lynch e Splet já haviam feito em The grandmother, o diretor William Friedkin tratou a voz como efeito sonoro. Quando possuída, a menina de 12 anos do filme, Regan (Linda Blair), foi dublada pela atriz veterana Mercedes McCambridge, com truques de fonoaudiologistas (CARREIRO; MIRANDA, 2015, p. 124).

O filme foi um dos que mais contribuíram para tornar consciente a autonomia da voz em relação ao corpo no cinema, explicitando a artificialidade dessa relação usualmente percebida como um registro meramente realista e condutor da narrativa. $O$ filme valoriza os vários significados não semânticos da voz, como respiração, timbre, sotaque, textura acústica e intensidade (ibidem, p. 125).

Slavoj Žižek (2000) vai mais longe em termos de autonomia da voz e defende que ela tem uma dimensão traumática por não ser uma parte orgânica do corpo humano. Ele reconhece algo de ventriloquista quando falamos, como se uma força externa tomasse posse de nosso corpo. Ele usa o exemplo de Regan, em O exorcista, como o de alguém que foi possuído por uma voz, em sua dimensão obscena (FIENNES, 2006).

Da boca da menina saem vozes outras, simultâneas à de McCambridge, trabalhadas com efeitos conhecidos, como execução de trás para frente e redução de velocidade, como evidencia a cena em que um dos padres grava a voz da menina e o registro revela mais vozes, em geral guturais e falando línguas irreconhecíveis. O horror surge do estranhamento dessa solução. Friedkin buscou tornar ambígua a presença de música e efeitos sonoros, outra estratégia reconhecível nas ambiências de Splet, se não na percepção do público, na forma como trabalhava seus efeitos.

Enquanto acompanhamos o contato do padre Merrian (Max von Sydow) com representações do mal (um pequeno amuleto maléfico e, posteriormente, a estátua de um demônio), a atmosfera sonora mescla sons ritmados de ferreiros, burburinhos, cantos típicos, vento, passos e efeitos diversos, orquestrados com sutileza e lógica musical (CARREIRO; MIRANDA: 2015, p. 128-129).

A animalidade ou bestialidade na voz confirmam a maldade e a agressividade de personagens que antes as desconheciam ou dissimulavam. A voz funciona como um elemento adicional que a aproxima do reino animal selvagem, mais ainda do medo humano desses seres que não funcionam segundo suas regras de civilidade, o que confirma, em caráter de ameaça, o que a imagem já mostra: personagens iradas e deformadas. Não se trata de um efeito de verossimilhança, é fato, mas ainda é um efeito sincrônico às imagens, que causa pouco estranhamento, se causar algum.

Outra vantagem dos sons de origem ou de referência animal em sobreposição ou substituição da voz, quando não há chance de haver algum bicho em cena nem fora do quadro, é a "leitura" que eles propiciam, ao espectador, por meio da audição. São sons 
orais, que vêm de bocas, mesmo que não humanas. Sons de outras fontes da natureza ou mecânicos das mais diversas origens poderiam confundir as plateias, fazendo-as achar que partem da diegese extracampo, num volume superior ao da voz das personagens.

\section{Ecos de um gênero}

Entender melhor o cinema de David Lynch é primordial para que se possa fazer aproximações entre ele e as teorias sobre o horror ficcional, assim como sobre os preceitos e as práticas recorrentes do gênero do horror fílmico. O diretor opera numa zona fronteiriça, limítrofe ${ }^{1}$, ao combinar elementos de ilusionismo da narrativa clássica e antiilusionismo, estes inspirados em movimentos de vanguarda do cinema (FERRARAZ, 2003, p. 165). Também se pode reconhecer combinações de elementos de gênero em seus filmes, entre as quais estão o surrealismo, mas também influências do horror fílmico, muitas vezes, pelo viés sobrenatural.

Adam Lowestein (2014) reconhece influências recíprocas desses dois gêneros no cinema, e Lynch como um cineasta que mesclou essas duas bases. O autor se baseia no conceito de surrealismo etnográfico de James Clifford, que liga os monstros da ficção aos grupos sociais e políticos de exceção.

Em vez de reforçar limites claros entre o eu e o outro, familiar e estranho, doméstico e exótico, o surrealismo etnográfico se propõe a localizar o outro no eu, o estranho no familiar, o exótico no doméstico (ibidem, p. 521).

O autor reconhece grandes contribuições ao imaginário surrealista do horror em vários cineastas, entre eles, Lynch (ibidem, p. 520). Lowestein (ibidem, p. 526) afirma que o surrealismo vive numa terra de sombras entre o sonho e a realidade.

Barbara Creed (2007) cita o fascínio de Lynch pelo poder do surrealismo e a montagem de choque para abrir a imaginação. "O filme de horror, claro, se aproximou ironicamente por décadas do lado sombrio e aflitivo do surrealismo" (ibidem, p. 115). A autora cita a visão do cineasta Clive Barker de que o filme de horror dá forma às principais qualidades estéticas do surrealismo e é o último refúgio do surreal, para então exemplificar com a série $A$ hora do pesadelo (A nightmare on Elm Street, EUA, 1984-2003), que se situa num mundo dos sonhos em que se torna impossível distinguir realidade de fantasia (ibidem, p. 117). Ela inclui o caso de Lynch em sua análise. “David Lynch é particularmente ligado ao poder do filme de colapsar sonho e realidade e operar de acordo com a lógica dos sonhos" (ibidem, p. 119), interessado no horror sob a superfície aparentemente normal da vida cotidiana de subúrbio americano (ibidem, p. 128).

1 Lynch mescla elementos de ilusionismo e antiilusionismo, narrativa convencional e construções de experimental. Ele cria um conjunto complexo, com múltiplos sentidos, a partir da combinação dessas partes. 
Lynch prioriza a criação de atmosferas de dúvida em relação à fluidez e à clareza narrativa. São atmosferas inexplicáveis de um nível considerável de pavor de forças externas desconhecidas - o que faz lembrar as atmosferas sonoras de Lucrecia Martel, trabalhadas como no horror -, embora mais desconfortantes que necessariamente empolgantes. Seu cinema se apoia mais no estranhamento do que em efeitos que causem surpresa e susto na plateia. Isso mantém o cinema de Lynch no universo fantástico, por se apoiar na incerteza, na hesitação de quem só conhece as leis naturais, diante de uma ocorrência aparentemente sobrenatural (TODOROV, 2007, p. 31).

Outro elemento estrutural e recorrente da obra de Lynch é o duplo, recorrente no universo do horror literário e, posteriormente, cinematográfico. Ele aparece mais claramente a partir das personagens de Twin Peaks (1990-1991), mas desde cedo está presente em sua obra por meio de construções cênicas e sonoras, propondo sentidos pelo menos duplos. Para Žižek (2000, p. 24), em Estrada perdida (1997), Lynch decompõe o sentido comum de realidade por meio da fantasia numa relação horizontal, não mais vertical. Mas esse é um filme posterior à parceria entre Lynch e Splet. Foi a partir dessa verticalidade de duplo sentido que o som usado como contraponto da imagem permitiu a criação de atmosfera estranha e desconfortável à compreensão lógica em seus filmes iniciais e, mais tarde, tornou-se marca registrada do sound design de Splet para o diretor.

Há um jogo ambíguo entre o som diegético e extradiegético em Veludo azul, em que um plano de detalhe de besouros num gramado traz tal amplificação do som que eles produzem, no qual se tem a sensação de se tratar de um som extradiegético (FERRARAZ, 2003, p. 51-52)². A fragmentação é um elemento essencial do cinema de Lynch, seja ela de narrativa, de imagem e som ou ambas (ibidem, p. 76). Uma junção de elementos distintos, não raro contraditórios, nos limites do sublime e do grotesco, um perfil surrealista que recupera o que André Breton identificou como beleza convulsiva (ibidem, p. 80).

Lynch busca revelar em seus filmes o mundo por trás do que os olhos anestesiados pela realidade cotidiana não conseguem perceber, a exemplo de Luis Buñuel e Salvador Dalí. Ele vai fundo na realidade aparente, trazendo à tona o que se esconde por trás, por baixo, dos lados dessa normalidade, mesmo que tal processo gere o desconforto da revelação de aspectos sinistros, desagradáveis e violentos (ibidem, p. 84). É essencial destacar a importância do duplo (doppelgänger) no cinema de Lynch, o que o sound design de Splet atende como camada adicional de suas tramas e estrutural de seu estilo de direção. Tema recorrente no Romantismo literário e, depois, nos filmes expressionistas da Alemanha, o duplo acabou por influenciar o ciclo clássico do horror cinematográfico nos Estados Unidos.

Na obra de Lynch, o duplo se manifesta como alguém real, imaginado ou multiplicado em vários personagens complementares, faces de uma personalidade em conflito (ibidem, p. 94). Simultaneamente, voyeurismo e exibicionismo criam dúvida sobre o que é real e

2 E, de fato, é. Na verdade, trata-se da somatória dos sons de 14 tipos de inseto distintos editados para serem ouvidos como se fossem só os do tipo de besouro na imagem (KROEBER, 2016: 223). Mas a amplificação do volume é evidente. 
o que é cópia, o material e o abstrato, corpo e alma, imagem e reflexo (ibidem, p. 102). Lynch lança mão da incerteza intelectual para criar uma atmosfera sinistra, como no conto $O$ homem da areia, de E. T. A. Hoffmann, sem deixar claro se o que vemos são acontecimentos ou delírios das personagens (ibidem, p. 106). A recorrência em sua obra de corpos mutilados e entranhas, humanos ou não, aspecto grotesco comum ao horror fílmico, não visa a causar sustos, mas a incomodar e deturpar um universo cênico muitas vezes estética e comportamentalmente equilibrado e esmerado.

O som dos filmes de Lynch evidencia as fissuras da identidade e desloca o que vemos do que ouvimos (ibidem, p. 160), ironizando e parodiando referências. O cineasta trabalha com influências diversas em termos de estilo, forma e tema de diversos momentos. Além do expressionismo, do surrealismo e do horror propriamente dito, o filme noir também pode ser reconhecido na construção de variadas personagens. Ele mescla procedimentos ilusionistas, amplamente reconhecidos desde o chamado cinema clássico, como naturalismo ou realismo, e anti-ilusionistas, como aqueles inspirados nas vanguardas alemãs, em constante tensão entre distanciamento reflexivo e mergulhos sensoriais.

\section{Filmografia revista e a herança de Splet}

Filmes em que as personagens mantêm seu aspecto visual, mas suas vozes são ouvidas de forma distorcida, ainda hoje configuram raridade. E eis aí uma das características mais peculiares que o trabalho de Splet apresenta. No curta-metragem The Grandmother, Splet colocou latidos no lugar das vozes das personagens e esticou sons que deveriam ser gritos, de modo a fazer deles zunidos que quase musicam a cena. Na sequência inicial de $O$ homem elefante, há imagens de uma mulher gritando e se debatendo no chão (que parecem memória ou sonho), sobrepostas às de elefantes caminhando, enquanto, ao fundo, ouve-se bate-estacas. No entanto, a cena não apresenta a voz da mulher. Em vez disso, Splet adotou sons que parecem grunhidos animais - talvez dos próprios elefantes, mas sem sincronia clara (eles parecem calados na cena) - para sonorizar o grito de evidente desespero da mulher.

Em Duna é corriqueiro o uso de distorções da voz de personagens em tom de ameaça. Nenhuma outra alteração física visualmente perceptível as transforma além da voz, que sempre assume um tom rouco, semelhante a um grunhido, para revelar a bestialidade contida por trás de rostos de aparência impassível. Splet faz essas vozes reverberarem por todo o ambiente da cena. Tratada como efeito sonoro, a voz é também o som do ambiente, elemento sonoro exclusivo em cena.

Veludo azul traz, além de trechos mais peculiares no uso de sons não vocais, como a amplificação do som dos insetos no gramado, dois momentos em que a voz é tratada como efeito sonoro. Num deles, o personagem Jeffrey Beaumont (Kyle MacLachlan) tem um pesadelo com as vozes distorcidas de Frank Booth (Dennis Hopper) - este também 
com a imagem desfigurada - e Dorothy Vallens (Isabella Rossellini). Noutra cena de sexo, Dorothy pede a Jeffrey que bata nela. Jeffrey se recusa, ela se enfurece, ele fala em chamar a polícia, ela implora que Jeffrey não faça isso, surge brevemente a imagem de uma vela acesa ao vento. Há um embate entre os dois, e o tapa em Dorothy acaba acontecendo. Assim como em $O$ homem elefante, a cena passa a acontecer em câmera lenta. Um sorriso de prazer da moça é sonorizado com um efeito sonoro distorcido, que soa como uma mistura de rugido de animal e vento. Entra em cena uma imagem de explosão, que também aparece brevemente.

Em Twin Peaks (1990-1991), a criatividade do tratamento de vozes como se fossem efeitos sonoros já surge nas duas primeiras temporadas, além das cenas do quarto vermelho, mas de maneira muito esporádica. Algumas distorções e amplificações adotadas têm certa recorrência em produções com uso mais tradicional de efeitos sonoros. As aparições de Bob (Frank Silva), quase sempre rindo ameaçadoramente, trazem distorções bestiais e reverberação acentuada, em harmonia com suas expressões faciais, gestos e movimentação. Quando ele se apodera de Cooper, como de seu duplo, ao fim da segunda temporada, a atuação de MacLachlan equivale à de Silva (falecido em 1995). Já na $3^{\text {a }}$ temporada, de 2017, o ator adota uma interpretação fria e discreta, caracterizado apenas pelo cabelo comprido e por roupas mais informais que as do agente. De todo modo, ainda que não no caso dele, a voz continua protagonizando os momentos mais criativos do sound design, agora assinado pelo próprio Lynch ${ }^{3}$.

No capítulo 3.03, surge Naido (Nae Yuuki), mulher com uma pele inchada com cicatrizes sobre os olhos, que a faz agir como cega e reitera a tradição lynchiana da deformação física. Suas imagens e sua voz são entrecortadas como animação stop motion, mas de modo irregular. Ela fala para Cooper, e sua voz tem uma distância em relação à câmera e ressonância realistas para o ambiente amplo em que estão, não com a proximidade que o protagonismo da compreensão oral no cinema e na TV clássicos pede. A personagem causa surpresa, curiosidade e angústia pelo mistério do que tenta comunicar. Ao contrário, ela vive um experiência de provável horror como vítima, indicando saber de algo terrível que, no entanto, quase não consegue expressar por via oral de forma nenhuma. Sua presença e sua representação por si só não foram construídas de modo a despertar medo no espectador. O que a personagem sabe, provavelmente sim, mas só haverá esse efeito quando o que ela tenta em vão dizer for revelado.

Com Threnody for the Victims of Hiroshima, música instrumental de Krzysztof Penderecki, o capítulo 3.08 mantém uma atmosfera de tensão e medo com a primeira explosão atômica, no estado americano do Novo México. Mais adiante, pessoas vagam num posto de gasolina isolado de outras edificações. A luz e o som são entrecortados, o

3 É sintomático notar também que o diretor guarda, desde 1994 até hoje, parte das cinzas de Splet num console em seu escritório, reverência sintomática da sintonia fina entre os dois. Alguns capítulos retomam o quarto vermelho, mas há novos exemplos de experimentação de som a partir da voz (KROEBER, 2016: 249-250). 
que se assemelha a um efeito da radiação. Em 1956, um casal num carro é abordado por zumbis. A voz deles é distorcida, parece estática. Com típica tensão de ameaça, própria de filmes de terror, em um deles (Robert Broski) mata a recepcionista e o DJ de uma estação de rádio, espremendo seus crânios. Ao microfone da rádio, ele repete com voz gutural e metálica: "Esta é a água, e este é o poço. Beba tudo e desça. O cavalo é o branco dos olhos e o escuro por dentro". Pessoas que ouvem a transmissão da rádio em outros lugares despencam no chão, não se sabe se desmaiadas ou mortas.

Em todos os filmes, com especial destaque para Eraserhead, havia todo um cuidado de Splet com ambientes sonoros, frequentemente sons industriais e ventos, que não podem ser confirmados visualmente com o que está em quadro, talvez sugerindo fontes distantes da própria diegese, e isso se repete em Twin Peaks. Não são apenas efeitos sonoros que causem efeito comparável aos de filmes de horror, mas também de estranhamento, descompasso entre imagens e sons. Splet reserva à voz e aos efeitos sonoros que a substituem o intuito de estabelecer sonoridades de ameaça e agressividade.

Nas duas primeiras temporadas de Twin Peaks, algumas das soluções sonoras resgatam procedimentos típicos do horror fílmico, como gotas com som amplificado, efeitos de trovão para incutir sensação de temor, e distorção vocal que revela bestialidade em meio a expressões assustadoras de personagens em situações de agressividade. Por outro lado, a inovação no sound design se dá porque a voz também é distorcida para um estranhamento declaradamente onírico das cenas no quarto vermelho, solução que Splet ajudou Lynch a elaborar.

Nessas temporadas de Twin Peaks, com o cineasta atribuindo a terceiros a direção de vários capítulos, numa mídia de alcance muito maior que o circuito de exibição de seus filmes, essas construções de efeitos sonoros são mais espaçadas e o clima soturno de tristeza e estranhamento depende muito da trilha musical, mérito, em grande parte, do compositor Angelo Badalamenti. Os efeitos sonoros, tão valorizados na parceria de Lynch e Splet, voltaram mais diversificados na temporada de 2017, tendo a voz como principal matéria-prima, em composições que surpreendem pela estranheza, por vezes, criando contrapontos em relação às imagens, desta vez mais trabalhada que a do vilão Bob de 1990-1991. O horror sonoro que Bob representava naqueles anos deu lugar aos zumbis de 1956. O duplo mau de Cooper foi configurado como um vilão quase tradicional humano, de voz normal, diferindo por sua origem e fim.

Gritos, tão recorrentes nos filmes de terror, já haviam sido subvertidos por Splet em nome do deslocamento narrativo em $O$ homem elefante e Veludo azul. Diferentemente do horror, Lynch faz de personagens com aparência monstruosa seres dóceis e frágeis, a exemplo do John Merrick, de O homem elefante e o bebê de Eraserhead. Houve raras oportunidades para o sound designer flertar com construções sonoras típicas do horror, como as vozes femininas bestializadas de Duna, que, diferentemente de O exorcista, não acompanhavam alterações físicas visíveis das personagens. 
Entretanto, em comum com um recurso sonoro tradicional dos filmes de horror, os sons extracampo, Splet criou atmosferas de mistério em vários momentos dos filmes de Lynch que sonorizou. Porém, o resultado trafega muito mais por instâncias de descompasso, em relação ao que está visualmente em cena, do que de ameaça e medo, que prenunciam um susto. É a hesitação do fantástico de que trata Todorov. O mais próximo que ele chega de efeitos sonoros conhecidos nos filmes do gênero, é seu trabalho com vozes trocadas por efeitos sonoros de ambiente, que reforçam agressividade. Splet se pauta por um uso nada naturalista de som nessas cenas.

\section{Conclusão}

Vimos que, ao optar por Lynch, Splet busca uma combinação de efeitos sonoros que nem sempre deixa clara sua origem, nem mesmo o que pretendem informar com eles (se é que trazem um sentido claro). Essa combinação leva a mesclas sonoras sem sincronização obrigatória com a imagem. Ela combina com a criação de atmosferas que prescindem de explicação lógica dos filmes do diretor. Tal diacronia combina também com o tema do duplo, que o cineasta frequentemente explora em seus filmes, para revelar o que não é facilmente percebido sobre personagens e os lugares onde vivem. Seu trabalho, nessa fase, enquadra-se no conceito de cinema limítrofe, defendido por Ferraraz, em que os filmes contrastam elementos distintos que os colocam entre fronteiras de gênero. O sound design de Splet é um dos principais elementos limítrofes nos filmes de Lynch.

Ao trazer construções sonoras assinadas pelo próprio diretor, a temporada de 2017 de Twin Peaks aprofunda e chega a radicalizar o sound design de efeitos sonoros desenvolvido por ele e por Splet num nível de quantidade, variedade e (pensando-se em ficção televisiva) ousadia, que não se via desde o curta-metragem The grandmother, 47 anos antes. Lynch também intensificou o uso de elementos da trama com relação mais clara tanto com o horror fílmico quanto com o surrealismo. Enquanto Bob era uma única entidade cruel que influenciava personagens a atormentar e ceifar vidas nas duas primeiras temporadas, a terceira temporada torna essa influência uma força maligna cada vez mais ampla e sem sinal de limites, possível efeito decorrente de uma explosão atômica - talvez consequência de um poder maior de outra dimensão.

A volta da série também reitera o duradouro caráter de exceção e inovação da identidade sonora que Lynch desenvolveu com Splet. Mesmo passadas décadas, suas estratégias continuam surpreendendo, no cinema ou na TV, mesmo que Lynch tenha reduzido consideravelmente suas experimentações sonoras por obra, já desde Eraserhead. Em termos de som, o horror se manifesta por vozes trabalhadas com estratégias conhecidas do gênero, como a distorção eletrônica de efeito rascante do zumbi dos anos 1950. O resultado mais inusitado é, além do já conhecido trabalho de vozes como efeitos sonoros nas cenas do quarto vermelho, o das tentativas em vão de diálogo de Naido. Predomina 
o estranhamento que confunde sem assustar. Sejam as falas do anão, Laura e Phillip Gerard (Al Strobel), gravadas ao contrário e com significado a se decifrar, ou a incomunicabilidade aflita de Naido. A não compreensão torna a oralidade parte estrutural do mistério da série e do fascínio pelo trabalho de Lynch.

Laura Loguercio Cánepa Correio e Rogério Ferraraz são professores do Programa de Pós-Graduação em Comunicação da Universidade Anhembi Morumbi.

Ilcanepa@anhembi.br

rogerioferraraz@uol.com.br

Fabiano Pereira de Souza é doutorando no mesmo programa.

fabian59@gmail.com

\section{Referências:}

CARREIRO, R. Sobre o som no cinema de horror: padrões recorrentes de estilo. C-Legenda. v. 1, n. 24, Niterói, 2011. p. 43-53.

CARREIRO, R.; MIRANDA, S. R. Representações sonoras do diabo no cinema: vozes múltiplas e músicas mínimas em O Exorcista. Revista Famecos. v. 22, n. 4, Porto Alegre, out., nov. e dez. 2015. p. $119-134$.

CREED, B. The untamed eye and the dark side of surrealism: Hitchcock, Lynch and Cronenberg. In: HARPER, G.; STONE, R. The Unsilvered Screen: Surrealism on Film. Londres: Wallflower Press, 2007. p. 115-133.

FERRARAZ, R. O cinema limítrofe de David Lynch. Tese (Doutorado). PUC-SP, São Paulo, 2003.

FIENNES, S. The Pervert's Guide to Cinema. Amoeba Film, Kasander Film Company, Lone Star Productions, Mischief Films, 2006 [produção]. 1 DVD (150 min.), cor.

KROEBER, A. Entrevista. In: SOUZA, F. P. Alan Splet: o sound design de Veludo azul e a polifonia de efeitos sonoros. Dissertação (Mestrado). Universidade Anhembi Morumbi, São Paulo, 2016.

LOWESTEIN, A. Horror's otherness and ethnographic surrealism: the case of The shout. In: BENSHOF, Harry M. (org.). A companion to the horror film. West Sussex: Wiley Blackwell, 2014. p. 519-535.

MANZANO, L. A. F. Do editor de som ao sound designer, os Ecos de uma Evolução. Filme Cultura n58, Rio de Janeiro, jan., fev. e mar. 2013.

MENDES, E. S. Entrevista. In: SOUZA, F. P. Alan Splet: o sound design de Veludo azul e a polifonia de efeitos sonoros. Dissertação (Mestrado). Universidade Anhembi Morumbi, São Paulo, 2016.

MORGAN, J. The biology of horror: Gothic literature and film. Carbondale: Southern Illinois University Press, 2002. 
SPADONI, R. The uncanny bodies: The coming of sound film and the origins of the horror genre. Los Angeles: University of California Press, 2007.

TODOROV, T. Introdução à literatura fantástica. São Paulo: Perspectiva, 2007.

ŽIŽEK, S. The art of the ridiculous sublime: on David Lynch's Lost highway. Washington: University of Washington: Walter Chapin Simpson Center for the Humanities, 2000.

Artigo recebido em 18/12/2018

e aprovado em 20/02/2019. 